\title{
Sistem Informasi Geografis Pemetaan Pasar Tradisional Daerah Kota Cilacap Berbasis Website
}

\section{Geographical Information System for Website-Based Mapping of Tradisional Markets in Cilacap City}

\author{
Indah Nuryohandi ${ }^{1}$, Agus Susanto ${ }^{2}$, Antonius Agung Hartono ${ }^{3}$ \\ 1,2,3 Teknik Informatika, Politeknik Negeri Cilacap \\ e-mail: indahnuryohandi@gmail.com ${ }^{1}$, agussusanto@pnc.ac.id ${ }^{2}$, ant.agung.hartono@pnc.ac.id ${ }^{3}$
}

\begin{abstract}
Abstrak
Pasar rakyat merupakan tempat bertemunya penjual dan pembeli yang ditandai adanya transaksi antara penjual dan pembeli secara langsung, baik melalui kios, los dan dasaran terbuka. Berdasarkan hasil penelitian di Dinas Perdagangan Koperasi Usaha Kecil dan Menengah (DPKUKM) dan Pasar, secara geografis keadaan dan lokasi pasar tidak tersedia gambaran yang jelas, serta belum adanya media yang digunakan oleh pihak pasar untuk menyampaikan informasi kepada penunjung dan sebaliknya dari pihak dinas ke pihak pasar. Penelitian ini bertujuan agar sistem informasi geografis berbasis website dapat membantu mempermudah kepala pasar dan dinas dalam menyampaikan informasi berita terkait pasar, dan sebagai media promosi untuk setiap pasar dalam mempromosikan kepada pengunjung. Pengembangan sistem menggunakan metode waterfall, metode blackbox, pengujian fungsionalitas fitur disis aktor, dan pengujian skenario. Hasil penelitian sistem ini dapat menampilkan informasi lokasi pasar berupa peta, menampilkan fasilitas yang ada di pasar dan peta pelapak.
\end{abstract}

Kata Kunci : Sistem Informasi Geografis, Metode Waterfall, Blackbox

\begin{abstract}
The people's market is a meeting place for sellers and buyers, which is indicated by direct transactions between sellers and buyers, either through kiosks, booths and open bases. Geographically, the information available at the Trade Office, Cooperatives, Small and Medium Enterprises (DPKUKM) and Market regarding the situation and location of the market is not clear, there is no media used by the market to convey information and manage the market. The market head delivers information verbally to the agency. System development uses the waterfall method, blackbox method, actor feature functionality testing, and scenario testing. This research aims to make a website-based geographic information system can help facilitate the head of the market and offices in conveying market-related news information, as a promotional medium for each market in promoting it to visitors. The results of this system research can display market location information in the form of maps, existing facilities in the market and pelapak maps.
\end{abstract}

Keywords: Geographical Information System, Waterfall, Blackbox

\section{Pendahuluan}

Pasar rakyat merupakan tempat bertemunya penjual dan pembeli yang di tandai adanya transaksi antara penjual dan pembeli secara langsung, baik melalui kios-kios, los dan dasaran terbuka yang dibuka atau disediakan oleh pasar. Kota Cilacap merupakan salah satu kabupaten yang ada di Jawa Tengah hingga kini masih mempertahankan keberadaan pasar tradisional karena keberadaanya masih sangat dibutuhkan oleh masyarakat kota cilacap dan sekitarnya. Pasar tradisional atau pasar rakyat yang terbesar di 5 kecamatan dan dikeloala oleh Dinas Perdagangan, Koperasi Usaha Kecil dan Menengah (DPKUKM) yaitu instansi pemerintah yang bertugas untuk mengelola dan mengoptimalkan pasar tradisional atau pasar rakyat yang ada di kabupten Cilacap[1].

Berdasarkan hasil observasi yang dilakukan di Dinas Perdagangan, Koperasi Usaha Kecil dan Menengah (DPKUKM), didapatkan informasi jika tiap pasar memiliki ciri khas berdasarkan komoditas barang yang diperjualbelikan. Selain itu tiap pasar juga memiliki jadwal operasionalnya pada hari-hari tertentu, seperti pasar karang kandri (wagean) yang dibuka pada hari yang jatuh di hari wage. Pasar yang tersebar di kota Cilacap juga dipantau oleh Dinas Perdagangan, Koperasi Usaha Kecil dan Menengah 
(DPKUKM). DPKUKM bertugas untuk memantau pasar dengan tujuan mengetahui informasi apa saja yang ada di pasar, seperti jumlah pelapak (sarana dan prasarana) serta memantau langsung ke lokasi pasar[2].

Informasi geografis pasar mengenai keadaan dan lokasi pasar belum tersedia dan pihak dinas ataupun pasar tidak memiliki media untuk menyampaikan informasi kepada pengunjung. Selain permasalahan-permasalahan tersebut, belum adanya sistem yang mengelola informasi mengenai pasar, membuat pihak dinas terkait harus menunggu pihak kepala pasar mendatangi pihak dinas pasar secara langsung untuk menyampaikan informasi mengenai pasar-pasar tersebut secara lisan, Oleh karena itu penulis melakukan penelitian untuk membangun "Sistem Informasi Geografis Pemetaan Pasar Tradisional Daerah Kota Cilacap Berbasis Website". Yang diharapkan sistem dapat memberikan kemudahan bagi pengunjung sebagai pengguna untuk memperoleh informasi serta melakukan pengaduan terkait fasilitas yang ada di pasar di daerah kota Cilacap. Sistem ini dapat membantu pelanggan untuk mengetahui informasi lokasi pasar, membantu pengunjung untuk mengetahui waktu operasional dari masing-masing pasar dan membantu pengunjung untuk mengetahui fasilitas-fasilitas yang dimiliki dari masing-masing pasar serta membantu pelanggan untuk mengetahui informasi jumlah toko dan pelapak yang ada di pasar tersebut, sehingga informasi dapat ter-update secara langsung. Dengan demikian dapat memudahkan pengunjung sebagai pengguna untuk dapat melihat informasi mengenai pasar yang ada di kota Cilacap.

Pasar Tradisional merupakan pasar yang dibangun dan dikelola oleh Pemerintah, Pemerintah Daerah, Swasta, Badan Usaha Milik Negera dan Badan Usaha Milik Daerah termasuk kerjasama dengan swasta dengan tempat usaha berupa toko, kios, los, dan tenda yang dimiliki/dikelola oleh pedagang kecil, menengah, swadaya masyarakat atau koperasi dengan usaha skala kecil, modal kecil dan dengan proses jual beli barang dagangan melalui tawar menawar[3]. Sistem Informasi Geografis digunakan dalam memahami, menganalisis dan mengelola data spasial terdistribusi yang kemudian dipetakan ke suatu wilayah geografis dimulai dengan tujuan menghasilkan peta digital[4]. Google Maps API (Application Programing Interface) merupakan salah satu fasilitas dari google yang menyediakan layanan pemetaan suatu daerah. Pemetaan kemampuan dan mudah digunakan. Kelengkapan lain pendukung peta tersebut seperti layanan informasi bisnis, jasa, layanan publik, jalan, lokasi, dan lain-lain[5]. Rekayasa Perangkat Lunak (Software Engineering) merupakan pembangunan dengan menggunakan prinsip atau konsep rekayasa dengan tujuan menghasilkan perangkat lunak yang bernilai ekonomi yang dipercaya dan bekerja secara efisien menggunakan mesin[6].

Penelitian sebelumnya terkait dengan sistem yang dikembangkan yaitu dengan judul "Aplikasi Sistem Informasi Geografis (SIG) Untuk Pemetaan Pasar Tradisional Di Kota Semarang Berbasis Web". memudahkan masyarakat luas khususnya masyarakat kota semarang sebagai sarana informasi yang efektif serta mendukung kegitan pelayanan instansi terkait dengan dinas pasar kota Semarang, membantu mengetahui persebaran pasar tradisional di kota Semarang, dan membantu mendeskripsikan tentang pasar tradisioanal dan informasi pasar tradisioanal di kota semarang[7].

Penelitian lainnya terkait dengan sistem yang dikembangkan yaitu penelitian dengan judul "Sistem Informasi Geografis Pemetaan Masjid di Samarinda Berbasis Website". Penelitian ini bertujuan untuk membantu menampilkan informasi masjid yang ada di kota Samarinda dengan filter pencarian info kegiatan dengan tanggal kegiatan tertentu, dan beradasarkan kecamatan. Aplikasi ini juga dapat membantu menampilkan informasi masjid jarak terdekat dari posisi user berada sesuai filter pencarian dan dilengkapi estimasi jarak perjalanan serta petunjuk arah dan berfungsi sebagai sistem infomasi masjid di Samarinda, di dalamanya terdapat informasi masjid, posisi masjid, dan info kegiatan yang ada di masjid[8].

Penelitian terkait yang ketiga dengan judul "Sistem Informasi Geografis (SIG) Pemetaan Sekolah Berbasis Web di Kecamatan Wonodadi Kabupaten Blitar." Sistem yang dibuat dapat membantu memudahkan pencarian lokasi sekolah di kecamatan Wonodadi, sistem ini dapat menampilkan letak sekolah dari tingkat sekolah dasar, menengah pertama dan menengah atas. Membantu masyarakat atau penguna dalam mengetahui informasi mengenai sekolah di kecamatan Wonodadi, implementasi sistem ini menujukan bahwa sistem informasi geografis ini memiliki desain yang cukup bagus dengan memeperoleh presentase sangat setuju sebesar $43,58 \%$, setuju sebesar $42,30 \%$, dan biasa sebesar $14,10 \%$. Penulis menggunakan metode waterfall untuk melakukan penelitian[9].

Penelitian yang ke empat terkait dengan judul "Sistem Informasi Geografis Pemetaan Pemasaran Sembilan Bahan Pokok Pada Kabupaten Bandung Barat". Sistem ini dikembangkan serta penambahan fungsi-fungsi dari komponen Sistem Informasi Geografis seperti monitoring sebaran akan kesenjangan bahan pokok yangmenjadikebutuhan sehari-hari[10].

Penelitian yang ke lima terkait dengan judul "Rancang Bangun Sistem Informasi Geografis Pemetaaan Toko Oleh-oleh dan Souvenir Khas Bangka di kota Pangkalpinang". Sistem informasi geografis ini dapat 
digunakan untuk pemetaan toko oleh-oleh dan souvenir khas Bangka di kota Pangkal pinang. Sistem yang dibuat dapat membantu mempermudah wisatawan dalam memperoleh informasi mengenai toko oleh-oleh yang akan dikunjungi, dapat membantu pemerintah untuk menganalisa pemetaan di wilayah kota Pangkalpinang. Tetapi sistem ini tidak terikat dengan Dinas Pariwisata sehingga pihak dinas tidak dapat mempromosikan objek wisata yang ada di kota Pangkal pinang[11].

Perbedaan dari penelitian sebelumnya sistem ini yaitu "Sistem Informasi Geografis Pemetaan Pasar Tradisional Daerah Kota Cilacap Berbasis Website" dapat menampilkan persebaraan lokasi pasar yang ada di kota Cilacap selain itu juga dapat menampilkan pemetaan denah didalam pasar, sistem ini juga dapat digunakan sebagai media promosi bagi setiap pasar yang ada di kota Cilacap. Metode peneliti yang digunakan yaitu metode waterfall, aplikasi yang digunakan untuk mebuat peta yaitu Google Maps API dan untuk pengujian sistem menggunakan metode Blackbox. Kelebihan penelitian ini dari penelitian sebelumnya adalah selain dapat melakukan pemetaaan sistem ini juga dapat membantu dinas untuk mendapatkan informasi dari pihak pasar, membantu pengunjung untuk mengetahu lokasi para pedagang yang ada di dalam pasar dengan adanya denah didalam pasar.

\section{Metode Penelitian}

Metode yang digunakan pada penelitian ini yaitu menggunakan metode waterfall yaitu suatu proses pengembangan perangkat lunak berurutan, di mana kemajuan dipandang sebagai terus mengalir ke bawah (seperti air terjun) melewati fase-fase perencanaan, pemodelan, implementasi (konstruksi), dan pengujian. Model air terjun (waterfall) menyediakan pendekatan alur hidup perangkat lunak secara sekuensial atau terurut. Berikut adalah tahapan-tahapannya sebagai berikut:

1. Analisis Kebutuhan Perangkat Lunak

Dalam melakukan analisis, dilakukan pengumpulan data baik melalui pustaka maupun berdasarkan masalah yang terjadi di lapangan. Analisis kebutuhan pada sistem Informasi geografis pemetaan pasar tradisional daerah kota cilacap berbasis website dibagi menjadi tiga yaitu kebutuhan kepala pasar, kebutuhan dinas dan kebutuhan pengunjung.

\begin{tabular}{|c|c|c|}
\hline No & User & Hak akses \\
\hline 1. & Kepala Pasar & $\begin{array}{ll}\text { 1. } & \text { Melihat data pasar } \\
\text { 2. } & \text { Melihat berita pasar } \\
\text { 3. } & \text { Melakukan input berita pasar } \\
\text { 4. } & \text { Melengkapi data pasar } \\
\text { 5. } & \text { Melihat Pengaduan } \\
\text { 6. } & \text { Melakukan login }\end{array}$ \\
\hline 2. & Dinas & $\begin{array}{ll}\text { 1. } & \text { Registrasi data kepala pasar } \\
\text { 2. } & \text { Melihat data pasar } \\
\text { 3. } & \text { Melihat berita pasar } \\
\text { 4. } & \text { Memasukkan data pasar } \\
\text { 5. } & \text { Melihat pengaduan } \\
\text { 7. } & \text { Melakukan input berita pasar } \\
\text { 8. } & \text { Melakukan login }\end{array}$ \\
\hline 3. & Pengunjung & $\begin{array}{ll}\text { 1. } & \text { Melihat data pasar } \\
\text { 2. } & \text { Melihat berita pasar } \\
\text { 3. } & \text { Melakukan registrasi } \\
\text { 4. } & \text { Memasukkan aduan } \\
\text { 5. } & \text { Melakukan login }\end{array}$ \\
\hline
\end{tabular}

2. Desain

Setelah melakukan tahap analisis, langkah berikutnya melakukan tahap desain sistem yang akan dikembangkan dengan menerjemahkan data yang dianalisa dalam bentuk use case diagram, sequance diagram dan Entity Relationship Diagram (ERD).

a. Desain Sistem menggunakan Usecase Diagram 


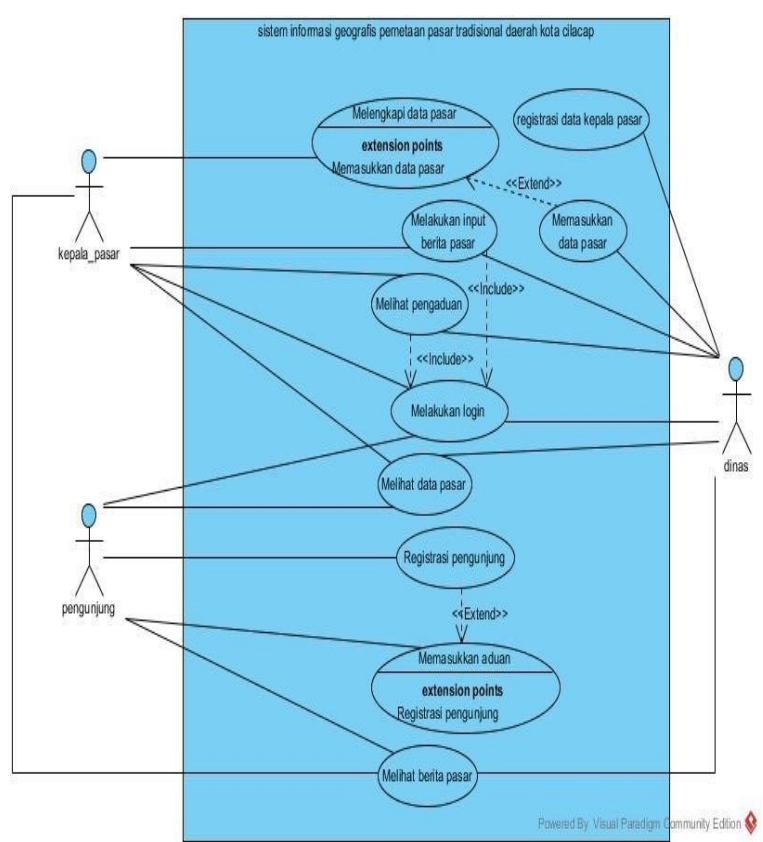

Gambar 1. Usecase Diagram Sistem Informasi Geografis Pemetaan Pasar Tradisional

Analisa sistem yang akan dikembangkan dalam sistem ini dapat dilihat pada gambar terdapat 3 aktor yaitu Kepala Pasar, Dinas dan Pengunjung serta terdapat 10 use case. Semua aktor tersebut harus melakukan login terlebih dahulu untuk menjalankan hak aksesnya.

b. Desain Database menngunakan ERD

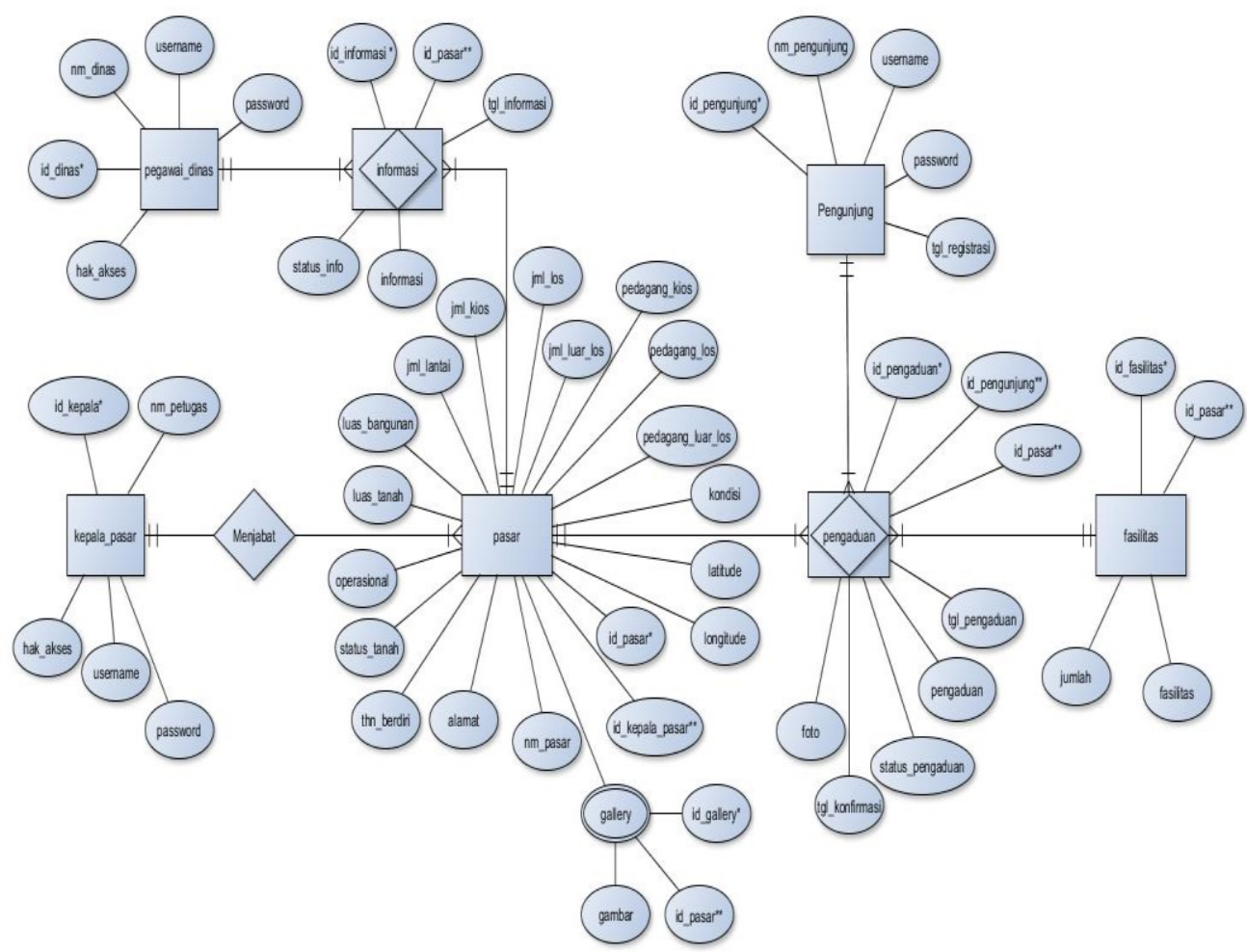

Gambar 2. Entity Relationship Diagram Sistem Informasi Pemetaan Geografis Pemetaan Pasar Daerah Kota Cilacap 
Berikut adalah penjelasan mengenai entity relationship diagram sistem informasi pemetaan geografis pemetaan pasar daerah kota cilacap.

1. Entitas pegawai dinas dengan pasar memiliki hubungan kardinalitas many-to-many yang dihubungkan dengan entitas informasi, dimana satu pegawai dinas dapat memberikan informasi untuk satu atau lebih pasar dan satu pasar dapat diberikan informasi oleh satu atau lebih pegawai dinas. Hasil hubungan many-to-many tersebut menghasilkan entitas assosiatif.

2. Entitas kepala pasar dengan pasar memiliki hubungan kardinalitas one-to-many, dimana satu kepala pasar menjabat satu atau lebih pasar dan satu pasar dijabat oleh satu kepala pasar.

3. Entitas pasar dengan fasilitas memiliki hubungan kardinalitas many-to-many yang dihubungkan dengan entitas pengaduan, dimana satu pasar memiliki lebih dari satu fasilitas dan satu fasilitas dapat dimiliki oleh lebih dari satu pasar. Entitas pasar memilki attribut multivalue yaitu gallery.

4. Entitas pengunjung dengan pasar memilki hubungan kardinalitas many-to-many, dimana satu pengunjung dapat memberikan informasi pengaduan pada satu atau lebih pasar dan satu pasar dapat diberikan pengaduan oleh satu atau lebih pengunjung. Hasil hubungan many-to-many tersebut mengahasilkan entitas assosiatif.

\section{Hasil dan pembahasan}

Hasil penelitian berupa aplikasi Sistem Informasi Geografis Pemetaan Pasar Tradisional Daerah Kota Cilacap. Pada aplikasi ini tampilan web dibagi menjadi 3 yaitu tampilan pengunjung, tampilan pihak dinas dan tampilan pihak pasar. Tampilan pihak dinas merupakan halaman yang berisi menu yang ada di web yang dapat diakses oleh pihak dinas perdagangan koperasi usaha kecil dan menengah yang mengelola pasar dapat membantu pihak dinas dalam mendapatkan dan memberikan informasi.

Tampilan pihak pasar merupakan halaman yang berisi menu yang ada di web yang dapat memberikan informasi kepada pihak Dinas Perdagangan Koperasi Usaha Kecil dan Menengah serta informasi terkait pasar tradisional yang ada di kota Cilacap kepada pengunjung.

a. Tampilan Halaman pengunjung
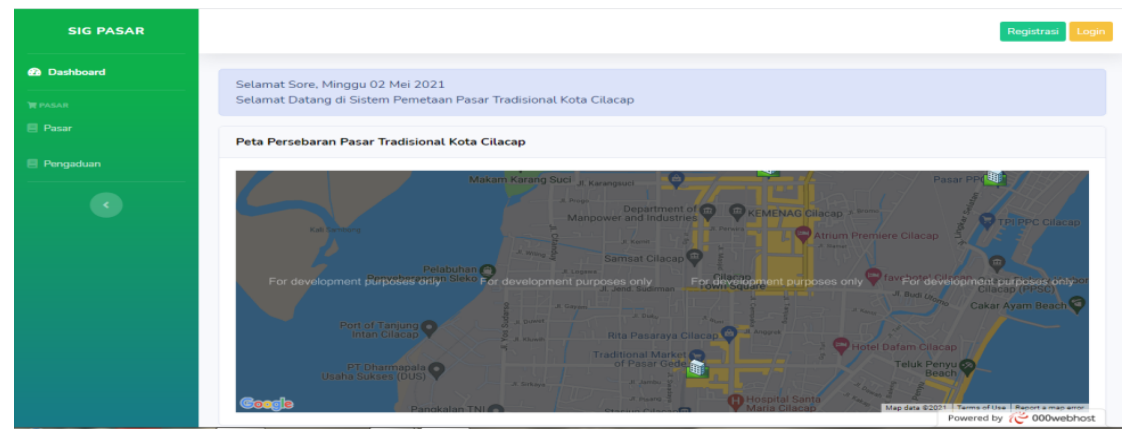

Gambar 3. Tampilan Halaman Pengunjung

Pada halaman ini pengunjung dapat mengakses peta persebaran pasar untuk mengetahui letak lokasi pasar di kota cilacap. Tidak hanya pengunjung, namun pihak dinas dan kepala pasar juga dapat mengakses halaman ini.

b. Halaman Daftar Pasar

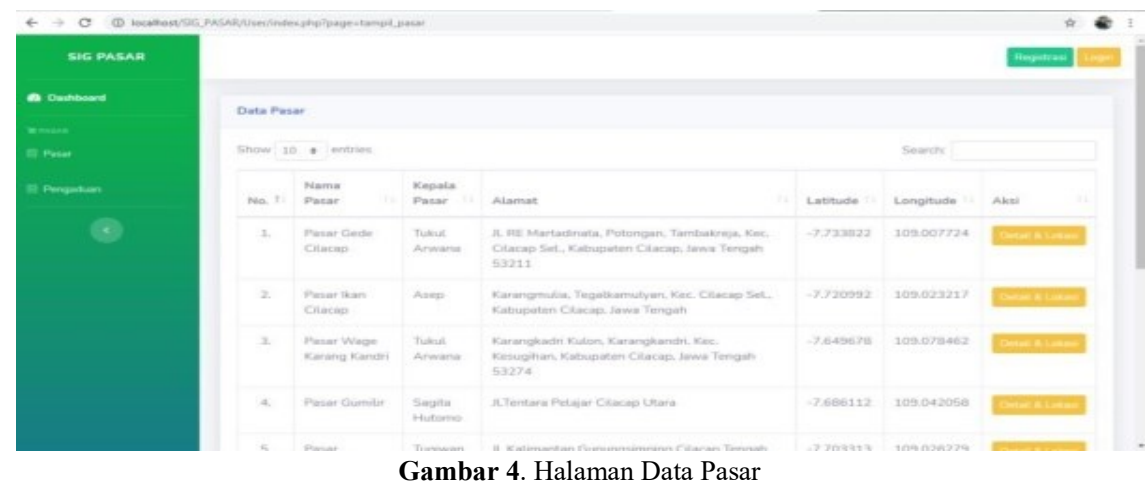

JINITA Vol. 3, No. 2, Desember 2021 
Pengunjung dapat melihat data yang telah dimasukkan oleh pihak kepala pasar. Pada tampilan tersebut terdapat button detail \& lokasi. Untuk melihat detail \& lokasi, pengunjung dapat menekan button detail \& lokasi dari setiap pasar. sehingga akan menampilkan data tentang pasar yang telah dipilih berupa lokasi pasar dan detail data pasar.

c. Halaman Detail dan Lokasi Pasar

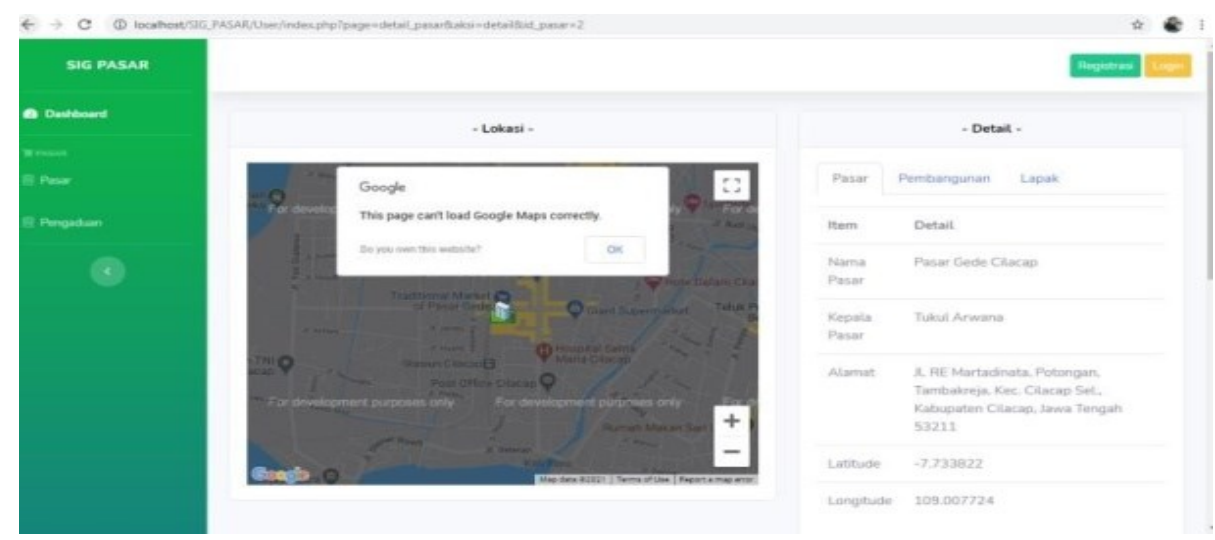

Gambar 5. Halaman Detail dan Lokasi Pasar

\section{Hasil Pengujian Metode Blackbox}

Untuk mendapatkan hasil pengujian sistem maka dilakukan pengujian, metode yang digunakan yaitu metode pengujian balckbox. Metode pengujian blackbox dilakukan untuk memperoleh gambaran kesesuaian antara input dan output. Pengujian ini lebih mengacu pada kebutuhan fungsional dari perangkat lunak. Berdasarkan hasil pengujian yang telah dilakukan, diketahui kegagalan yang ditemukan pada perangkat lunak yang dikembangkan. Berikut dibawah ini adalah tabel hasil pengujian perangkat lunak.

\begin{tabular}{|c|c|c|c|c|}
\hline No & Kegiatan & Hasil yang diharapkan & Hasil aktual & Keterangan \\
\hline 1 & Proses Login Pengunjung & $\begin{array}{l}\text { Jika berhasil melakukan login maka sistem akan } \\
\text { akan menampilkan halaman utama atau } \\
\text { Dashboard aktor }\end{array}$ & $\begin{array}{l}\text { Menampilkan halaman utama } \\
\text { pengujung }\end{array}$ & terpenuhi \\
\hline 2 & $\begin{array}{l}\text { Proses Login Dinas } \\
\text { dan Kepala pasar }\end{array}$ & $\begin{array}{l}\text { Jika berhasil melakukan login maka sistem akan } \\
\text { akan menampilkan halaman utama atau } \\
\text { Dashboard aktor }\end{array}$ & $\begin{array}{l}\text { Menampilkan halaman utama } \\
\text { dinas dan kepala pasar }\end{array}$ & terpenuhi \\
\hline 3 & $\begin{array}{l}\text { Proses Memasukkan } \\
\text { Data Pasar }\end{array}$ & Data pasar dapat ditambahkan ke databases & $\begin{array}{l}\text { Data pasar berhasil ditambahkan } \\
\text { ke database }\end{array}$ & terpenuhi \\
\hline 4 & $\begin{array}{l}\text { Proses Melengkapi } \\
\text { Data Pasar }\end{array}$ & Data pasar dapat dilengkapi melalui ubah data & $\begin{array}{l}\text { Data pasar berhasil dilengkapi } \\
\text { melalui ubah data }\end{array}$ & terpenuhi \\
\hline 5 & $\begin{array}{l}\text { Proses melakukan input } \\
\text { berita pasar }\end{array}$ & $\begin{array}{l}\text { Berita pasar dapat tersimpan dan ditampilkan } \\
\text { pada WebBrowser }\end{array}$ & $\begin{array}{l}\text { Berita asar berhasil tersimpan ke } \\
\text { database dan ditampilkan pada } \\
\text { halaman berita }\end{array}$ & terpenuhi \\
\hline 6 & $\begin{array}{lr}\text { Proses } & \text { Melakukkan } \\
\text { Registrasi } & \text { Data Kepala } \\
\text { Pasar } & \end{array}$ & $\begin{array}{l}\text { Data Kepala Pasar dapat tersimpan dan } \\
\text { ditampilkan pada WebBrowser }\end{array}$ & $\begin{array}{l}\text { Data kepala pasar berhasil } \\
\text { tersimpan dan ditampilkan pada } \\
\text { halaman keala pasar }\end{array}$ & terpenuhi \\
\hline 7 & $\begin{array}{l}\text { Proses Melakukan } \\
\text { registrasi } \\
\text { pengunjung }\end{array}$ & $\begin{array}{l}\text { Data pengunjung dapat tersimpan pada } \\
\text { database }\end{array}$ & $\begin{array}{l}\text { Data pengunjug berhasil } \\
\text { ditambahkan dan tersimpan pada } \\
\text { database }\end{array}$ & terpenuhi \\
\hline 8 & $\begin{array}{l}\text { Proses Memasukkan } \\
\text { Aduan }\end{array}$ & Pengunjung dapat melakukan aduan & $\begin{array}{l}\text { Data aduan dari pengunjung } \\
\text { dapat tersimpan dalam databse }\end{array}$ & terpenuhi \\
\hline
\end{tabular}

\section{Pembahasan pengujian}

Sistem telah berhasil dibangun sesuai dengan karakteristik dari sistem informasi geografis yang seharusnya yaitu memberikan informasi geografis yang lengkap mengenai lokasi pasar tradisional yang ada di kabupaten cilacap. System ini juga berbeda dengan system informasi geografis lainnya yang hanya 
sekedar menampilkan peta geografis pada system ini terdapat form aduan masyarakat yang dapat digunakan untuk menjadi bahan evaluasi bagi pengelola pasar tradisional di kabupaten cilacap.

\section{Kesimpulan}

Berdasarkan dari hasil pembahasan dan pengujian sistem informasi geografis pemetaan pasar tradisional daerah kota cilacap setelah diimplemetasikan dapat diambil kesimpulan yaitu Sistem ini dapat menampilkan informasi lokasi pasar berupa peta kemudian fasilitas yang ada di dalam pasar dan terdapat peta pelapak. Peta pelapak ini dapat membantu pengunjung untuk mencari lokasi pedagang. Sitem ini juga dapat membantu pengunjung untuk mengetahui informasi jumlah toko dan pelapak yang ada di pasar tersebut. Sistem ini dapat membantu kepala pasar dan dinas untuk mempermudah dalam menyampaikan informasi berita mengenai pasar. Sistem ini dapat sebagai media promosi untuk setiap pasar dalam mempromosikan pasar kepada masyarakat di kabupaten Cilacap.

\section{Daftar Pustaka}

[1] D. Cilacap, "Data Informasi Pasar di Kabupaten Cilacap," http://dpkukm.cilacapkab.go.id/datainformasi/pasar-di-kabupaten-cilacap/, 2017.

[2] D. Cilacap, "Profil Dinas Perdagangan, Koperasi Usaha Kecil dan Menengah," http://dpkukm.cilacapkab.go.id/profil/tupoksi/, 2017. .

[3] R. Indonesia, "Peraturan Presiden Republik Indonesia Nomor 112 Tahun 2007 Tentang Pengelolaan dan Pemberdayaan Pasar Tradisional, Pusat Perbelanjaan dan Toko Modern," Jakarta : Sekretariat Negara, 2007.

[4] A. S. Prabowo, L. Syafirullah, V. Prasetia, and H. Susanti, "Rancang Bangun Sistem Informasi Geografis Industri Kreatif Kabupaten Cilacap (SIKECAP),” JOINS (Journal Inf. Syst., vol. 6, no. 1, pp. 64-71, 2021, doi: 10.33633/joins.v6i1.4113.

[5] F. J, "Menjelajah Dunia dengan Google, Mesin Pencarian Informasi di Internet Tersebar di Dunia," Informatika, 2018.

[6] M. J. Hartono, “Analisis dan Desain Sistem Informasi, Edisi III,” Yogyakarta ANDI, 2010.

[7] A. P. Yuliani, Sylvia Tri; Sudarsono, Bambang; Wijaya, "Aplikasi Sistem Informasi Geografis (SIG) Untuk Pemtaan Pasar Tardisional di Kota Semarang Berbasis Web,” J. Geod. Undip, vol. 2, no. Sistem Informasi Geografis, pp. 240-252, 2016.

[8] S. Maharani, "Sistem Informasi Geografis Pemetaan Masjid Di Samarinda Berbasis Web," $J$. Inform., vol. 11, no. 1, p. 9, 2017, doi: 10.26555/jifo.v11i1.a5205.

[9] M. A. Husaini and W. Dwi P, "Sistem Informasi Geografis (Sig) Pemetaan Sekolah Berbasis Web Di Kecamatan Wonodadi Kabupaten Blitar," ANTIVIRUS J. Ilm. Tek. Inform., vol. 11, no. 1, pp. 50-64, 2017, doi: 10.30957/antivirus.v11i1.198.

[10] A. Kurniawan, F. Renaldi, F. R. Umbara, F. Sains, U. Jenderal, and A. Yani, "Sistem Informasi Geografis Pemetaan Pemasaran Sembilan Bahan Pokok Pada Kabupaten Bandung Barat,” pp. 877880, 2019.

[11] D. Y. Sylfania, E. B. Perkasa, and F. P. Juniawan, "Rancang Bangun Sistem Informasi Geografis Pemetaan Toko Oleh-Oleh dan Souvenir Khas Bangka di kota Pangkalpinang," Citisee, pp. 53-56, 2017. 